\title{
Accuracy of ultrasound estimated fetal weight formulae to predict actual birthweight after 34 weeks: prospective validation study
}

\author{
S Kumarasiri, R Wanigasekara, L Wahalawatta, L Jayasinghe, T Padeniya, T Dias \\ (Index words: validation, fetal weight, Sri Lanka)
}

\begin{abstract}
Objectives Late onset fetal growth restriction is often missed and is responsible for most intrauterine deaths. Ultrasound fetal biometry is routinely used to calculate estimated fetal weight (EFW). The aim of this study was to determine the accuracy of established ultrasound EFW formulae to identify small and large for gestational age fetuses when used after 35 weeks gestation.

Methods This was a prospective validation study done between January 2012 and July 2012 at General Hospital Ampara. An ultrasound examination was performed and fetal biometry was documented within one week before the delivery in well dated pregnancies. The mean of the differences between ultrasound EFW derived from 9 formulae and true birthweight and their standard error of mean (SE) were calculated for each formula. Systematic measurement error was assumed to exist if zero lay outside the mean difference $\pm 2 \mathrm{SE}$. To show the EFW frequency distribution, z-scores were calculated as the number of standard deviations an observed EFW measurement deviated from the mean for gestation.
\end{abstract}

Results A total of 393 pregnancies at gestational age between 35 and 41 weeks were recruited. Mean gestational age at the ultra sound scan was 39.36 weeks SD (1.05). All EFW formulae either under or over estimated the birthweight in singleton pregnancies. Almost all the formulae overestimated the fetal weight in low birthweight babies whilst underestimating the fetal weight in birthweight $>3500 \mathrm{~g}$. Campbell formula remained the only EFW formula without systematic error when measuring babies between $2500 \mathrm{~g}$ and $3500 \mathrm{~g}$. None of the EFW z-scores were normally distributed.

Conclusions This study found that all routinely used EFW formulae would either over or under estimate the fetal weight. Until an optimum EFW formula that suits the Sri Lankan population is determined, interpretation of ultrasound EFW should be done cautiously, especially in small for gestational age babies.

Ceylon Medical Journal 2013; 58: 116-121

\section{Introduction}

Small for gestational age (SGA) is defined when the fetal/ birthweight is below the 10th centile for a particular gestational age [1]. Even though the SGA label implies fetal growth restriction (FGR), such fetuses will include some constitutionally small fetuses as well. The proportion of constitutionally small fetuses to FGR fetuses will depend on the prevalence of such illnesses in the population [2]. FGR fetuses carry higher incidence of perinatal complications than appropriately grown counterparts. Late onset FGR is often missed and is responsible for most intrauterine deaths [1]. Therefore, accurate measurement of fetal weight is important in managing term FGR.

Ultrasonography is routinely used to estimate the fetal weight and is often used as a proxy to actual birthweight. Many ultrasound estimated fetal weight (EFW) formulae have been designed and these are based on different fetal biometric parameters [3]. Accuracy of ultrasound in predicting birthweight is more precise in early gestations, since at term there is significant deterioration of ultra sound resolution as the fluid to fetus ratio decreases, bony structures become increasingly calcified, and the vertex descends in the pelvis, making measurements of head circumference and biparietal diameter more difficult [4]. There is no systematic evaluation of accuracy of established ultrasound EFW in predicting actual birthweights in the Sri Lankan population. Despite this lack of robust evidence on the most suitable EFW formula for Sri Lankan population Hadlock formula 4 is routinely used to estimate fetal weight [5].

The aim of this study was to validate accuracy of established EFW formulae to predict actual birth weight after 34 weeks in a group of Sri Lankan pregnant women.

\section{Methods}

We prospectively studied women with uncomplicated singleton pregnancies. Ultrasound examination for fetal biometric measurements and wellbeing tests were offered within one week prior to delivery. All ultrasound

Department of Obstetrics and Gynaecology, District General Hospital, Ampara, Sri Lanka.

Correspondence: TD, e-mail: <thiran_dias@yahoo.com>. Received 15 January 2013 and revised version accepted 23 April 2013. Competing interests: none declared. 
assessments were taken between $35^{+0}$ and $40^{+0}$ weeks' gestation at the Obstetrics and Gynaecology Unit at District General Hospital, Ampara from January 2012 to July 2012. Pregnancies complicated with hypertensive disorders, diabetes mellitus, severe FGR and multiple pregnancies were excluded from the study. Approval was obtained from General Hospital, Ampara Ethics Review Committee. Informed consent was obtained before the study after adequate counseling.

\section{Ultrasound examinations}

Ultrasound scans for estimated fetal weight were scheduled within one week prior to date of delivery, estimated according to the first trimester dating by fetal crown-rump length in the spontaneously conceived pregnancies. They were performed by an accredited operator with experience in routine ultrasound examinations at term. Fetal biparental diamener (BPD), head circumference (HC), abdominal circumference (AC) and femur length (FL) measurements were taken according to the established guidelines [6]. All examinations were performed transabdominally using GE Logic 3 machine, one day prior to elective cesarean delivery and within maximum of 7 days prior to induction of labour. Any participant with ultrasound examination to delivery interval more than 7 days was excluded from the study. Birthweights were measured using properly calibrated LAICA weighing scale with unit of measure $\mathrm{kg}$; weight capacity $20 \mathrm{~kg}$; range of measurement $1 \mathrm{~kg}$ - $20 \mathrm{~kg}$; division $10 \mathrm{~g}$.

Ultrasound estimated fetal weights were calculated for commonly used nine EFW formulae [7-14]. Measurement error was defined as the difference in size between the estimated fetal weight calculated on the basis of ultrasound fetal biometry and actual weight after birth. The mean of these differences reflects systematic measurement error (i.e. systematic under- or overestimation of fetal size), whereas the standard deviation (SD) of the differences reflects the random measurement error. To determine if there was any systematic over or underestimation of fetal size, we calculated the $95 \%$ confidence interval (CI) of the mean difference (mean $\pm 2 \mathrm{SE}$, where $\mathrm{SE}=$ standard error). If zero lay within this interval no systematic measurement error was assumed to exist [15]. Normality of distribution was assessed using the Kolmogorov-Smirnoff test. Altman and Bland plot was created to see the level of agreement between actual birthweight and the difference of weight predicted by Hadlock formula 4 and Campbell formula. Furthermore, box plot was created to see the z-score distribution of difference of weight predicted by Hadlock formula 4 and Campbell formula.

\section{Results}

Three hundred and ninety three uncomplicated singleton pregnancies seen during the study period underwent ultrasound assessment between $35^{+0}$ and $40^{+6}$ weeks gestation. The median decimal gestational age at birth was 280 days (inter-quartile range $=6$ ) and mean duration from ultrasound scan to delivery was 3 days (range 0-6). Patient characteristics are given in Table 1. EFW from each establish formula was calculated separately. Formulae used for fetal weight estimation are given in Table 2.

The mean difference between the actual fetal weight and the estimated fetal weight measured by 9 commonly used EFW formulae are shown in Table 3. For better interpretation the difference is calculated for small and large for gestational age as well as for appropriately grown babies. Overall results show EFW either over or underestimate the actual birthweight. For low birthweight babies (birthweight $<2500 \mathrm{~g}$ ) all most all the EFW formulae overestimate the actual birthweight while underestimating birthweight for large for gestational age babies (birthweight $>3500$ g). In appropriately grown babies only the Campbell formula includes zero in the $95 \%$ CI of the mean difference, therefore it is the closest to the actual birthweight.

The level of agreement between actual birthweight and the difference between predicted and actual birthweight was given in Altman and Bland plot (Figure 1). The box plot of z-score distribution of difference of weight predicted by Hadlock formula 4 and Campbell formula is given in Figure 2. The percentage of babies within the acceptable range for differences between actual and predicted weight were $95.9 \%$ with Campbell formula and 94.4\% with Hadlock 4 formula.

Table 1. Characteristics of study population

\begin{tabular}{lc}
\hline Characteristics & $N=393$ \\
\hline Mean maternal age (SD) & $27.01(5.40)$ \\
BMI (Median and IQR) & $20(2.2)$ \\
Number of nulliparous women (\%) & $204(51.9)$ \\
$\begin{array}{l}\text { Mean duration (days) } \\
\text { from scan to delivery (range) }\end{array}$ & $3(0-6)$ \\
$\begin{array}{l}\text { Median GA at birth in days } \\
\text { (IQR in days) }\end{array}$ & 280 (6 days) \\
Birthweight in grams &
\end{tabular}

(Mean and 95\% CI)

2977 (2928.6 to 3025.4)

Number of babies delivered at each gestational age (mean)

$\begin{array}{lr}35^{+0} \text { to } 35^{+6} & 2\left(35^{+4}\right) \\ 36^{+0} \text { to } 36^{+6} & 5\left(36^{+3}\right) \\ 37^{+0} \text { to } 37^{+6} & 35\left(37^{+5}\right) \\ 38^{+0} \text { to } 38^{+6} & 66\left(38^{+5}\right) \\ 39^{+0} \text { to } 39^{+6} & 75\left(39^{+4}\right) \\ 40^{+0} \text { to } 40^{+6} & 207\left(40^{+5}\right) \\ 41^{+0} \text { to } 40^{+6} & 3\left(41^{+1}\right)\end{array}$

Mean birthweight

at 40 weeks $(95 \% \mathrm{CI})$

3140 (3097.2 to 3182.8)

SD: Standard deviation, IQR: inter quartile range, GA: Gestational age, 95\% CI: 95\% confidence interval. 
Table 2. Estimated fetal weight formulae used for fetal weight estimation

\begin{tabular}{ll}
\hline \multicolumn{1}{c}{ Study } & \multicolumn{1}{c}{ Formulae } \\
\hline Hadlock 1 (1984) [9] & $\log _{10} \mathrm{BW}=1.304+(0.0528 \times 1 \mathrm{AC})+(0.1938 \times \mathrm{FL})-(0.004 \mathrm{x} \mathrm{AC} \times \mathrm{FL})$ \\
Hadlock 2 (1985) [7] & $\log _{10} \mathrm{BW}=1.335-(0.0034 \times \mathrm{AC} \times \mathrm{FL})+(0.0316 \times \mathrm{BPD})+(0.0457 \times \mathrm{AC})+(0.1623 \times \mathrm{FL})$ \\
Hadlock 3 (1985) [8] & $\log _{10} \mathrm{BW}=7.326-(0.00326 \times \mathrm{AC} \times \mathrm{FL})+(0.0107)+(0.0438 \times \mathrm{AC})+(0.108 \times \mathrm{FL})$ \\
Hadlock 4 (1985) [8] & $\log _{10} \mathrm{BW}=0.3596+(0.00061 \times \mathrm{BPD} \times \mathrm{AC})+(0.0424 \times \mathrm{AC})+(0.174 \times \mathrm{FL})+(0.0064 \times \mathrm{HC})-$ \\
& $(0.00386 \times \mathrm{AC} \times \mathrm{FL})$ \\
Campbell (1975) [10] & $\log _{10} \mathrm{BW}=-4.564+(0.282 \times \mathrm{AC})-0.00331(\mathrm{AC})^{2}$ \\
Merz (1988) [11] & $\mathrm{EFW}=3200.40479-(157.07186 \times \mathrm{AC})+(15.90391 \times(\mathrm{BPD}))$ \\
Warsof (1977) [12] & $\log _{10} \mathrm{BW}=-1.599+(0.144 \times \mathrm{BPD})+(0.032 \times \mathrm{AC})-\left(0.111 \times(\mathrm{BPD})^{2} \times \mathrm{AC} / 1000\right.$ \\
Thurnau (1983) [13] & $\mathrm{EFW}=(\mathrm{BPD} \times \mathrm{AC} \times 9.337)-299.076$ \\
Shepard (1982) [14] & $\log _{10} \mathrm{BW}=(-1.7492+(0.166 \times \mathrm{BPD})+(0.046 \times \mathrm{AC})-(0.002646 \times \mathrm{AC} \times \mathrm{BPD})) \times 1000$ \\
\hline
\end{tabular}

BW: Birthweight, AC: abdominal circumference, FL: femur length, BPD: Biparietal diameter, HC: head circumference, EFW: estimated fetal weight

Table 3. The mean difference between observed (ultrasound EFW) and expected (actual birthweight)

\begin{tabular}{|c|c|c|c|c|c|c|c|c|c|}
\hline & Hadlock-1 [9] & Hadlock-2 [7] & Hadlock-3 [8] & Hadlock-4 [8] & Campbell [10] & Merz [11] & Warsof [12] & Thurnau [13] & Shepard [14] \\
\hline \multicolumn{10}{|c|}{ Overall results } \\
\hline $\begin{array}{l}\text { Mean } \\
\text { difference } \\
(95 \% \mathrm{CI})\end{array}$ & $\begin{array}{c}86.9 \\
(49.9 \text { to } \\
123.9)\end{array}$ & $\begin{array}{c}116.9 \\
(79.6 \text { to } \\
154.2)\end{array}$ & $\begin{array}{c}69.8 \\
(33.5 \text { to } \\
105.9)\end{array}$ & $\begin{array}{c}91.9 \\
\text { (55.9 to } \\
127.9)\end{array}$ & $\begin{array}{c}-47.3 \\
(-82.1 \text { to } \\
-12.4)\end{array}$ & $\begin{array}{c}228.2 \\
(192.7 \text { to } \\
263.8)\end{array}$ & $\begin{array}{c}-90.5 \\
(-134.5 \text { to } \\
-46.5)\end{array}$ & $\begin{array}{c}-510.3 \\
(-547.0 \text { to } \\
-473.7)\end{array}$ & $\begin{array}{c}62.8 \\
(19.2 \text { to } \\
106.4)\end{array}$ \\
\hline \multicolumn{10}{|c|}{ Birthweight $<2500 \mathrm{~g}$} \\
\hline $\begin{array}{l}\text { Mean } \\
\text { difference } \\
(95 \% \mathrm{CI})\end{array}$ & $\begin{array}{c}230.00 \\
\text { (148.9 to } \\
311.1)\end{array}$ & $\begin{array}{c}231.94 \\
(142.8 \text { to } \\
321.1)\end{array}$ & $\begin{array}{c}195.7 \\
(120.6 \text { to } \\
270.8)\end{array}$ & $\begin{array}{c}207.4 \\
(126.2 \text { to } \\
288.6)\end{array}$ & $\begin{array}{c}112.1 \\
(11.5 \text { to } \\
212.7)\end{array}$ & $\begin{array}{c}356.8 \\
\text { (244.3 to } \\
469.3)\end{array}$ & $\begin{array}{c}50.9 \\
(-90.4 \text { to } \\
192.3)\end{array}$ & $\begin{array}{c}-179.3 \\
(-267.8 \text { to } \\
-90.7)\end{array}$ & $\begin{array}{c}139.2 \\
(22.8 \text { to } \\
255.7)\end{array}$ \\
\hline \multicolumn{10}{|c|}{ Birthweight between $2500 \mathrm{~g}$ and $3500 \mathrm{~g}$} \\
\hline $\begin{array}{l}\text { Mean } \\
\text { difference } \\
(95 \% \mathrm{CI})\end{array}$ & $\begin{array}{c}109.8 \\
\text { (68.7 to } \\
150.9)\end{array}$ & $\begin{array}{c}141.5 \\
(99.6 \text { to } \\
183.3)\end{array}$ & $\begin{array}{c}92.3 \\
\text { (51.6 to } \\
132.9)\end{array}$ & $\begin{array}{c}115.5 \\
\text { (75.2 to } \\
155.8)\end{array}$ & $\begin{array}{c}-19.6 \\
(-56.1 \text { to } \\
16.9)\end{array}$ & $\begin{array}{c}257.5 \\
\text { (219.9 to } \\
295.1)\end{array}$ & $\begin{array}{c}-71.3 \\
(-119.6 \text { to } \\
-23.01)\end{array}$ & $\begin{array}{c}-489.5 \\
(-525.9 \text { to } \\
-453.1)\end{array}$ & $\begin{array}{c}88.9 \\
\text { (39.6 to } \\
138.1)\end{array}$ \\
\hline \multicolumn{10}{|c|}{ Birthweight >3500 g } \\
\hline $\begin{array}{l}\text { Mean } \\
\text { difference } \\
(95 \% \text { CI })\end{array}$ & $\begin{array}{c}-193.9 \\
(-299.3 \text { to } \\
-88.6)\end{array}$ & $\begin{array}{c}-148.6 \\
(-250.1 \text { to } \\
-47.1)\end{array}$ & $\begin{array}{c}-192.8 \\
(-297.6 \text { to } \\
-87.9)\end{array}$ & $\begin{array}{c}-168.3 \\
(-270.5 \text { to } \\
-66.2)\end{array}$ & $\begin{array}{c}-374.5(-469.5 \text { to } \\
-279.4)\end{array}$ & $\begin{array}{c}-80.4(-175.0 \\
\text { to } 14.2)\end{array}$ & $\begin{array}{c}-346.1 \\
(-463.7 \text { to } \\
-228.5)\end{array}$ & $\begin{array}{c}-953.9 \\
(-1032.8 \text { to } \\
-8.75 .1)\end{array}$ & $\begin{array}{c}-175.9 \\
(-297.4 \text { to } \\
-54.4)\end{array}$ \\
\hline
\end{tabular}

These differences were also calculated for the small and large for gestational age babies as well as for appropriately grown babies. 


\section{A Hadlock 4 formula}

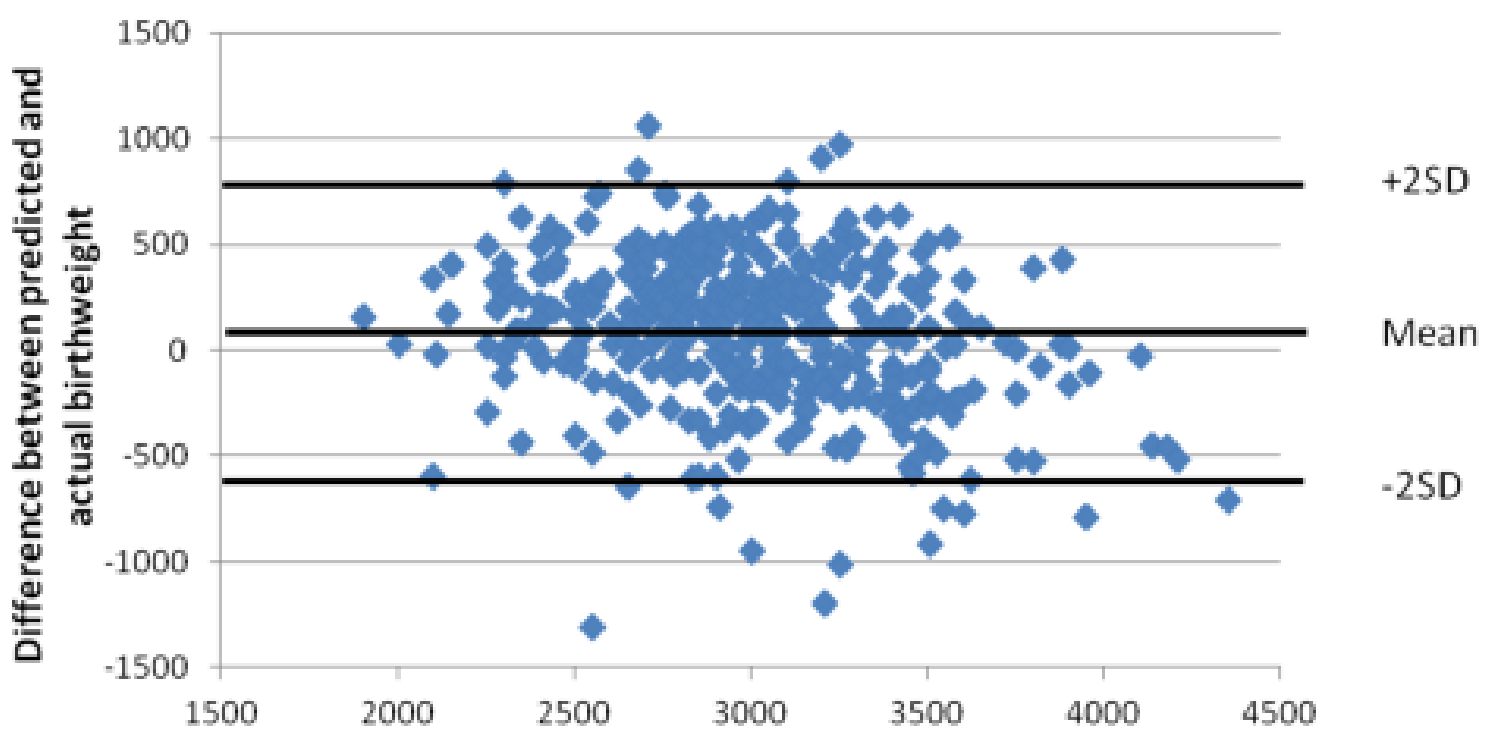

Birthweight

B

Campbell formula

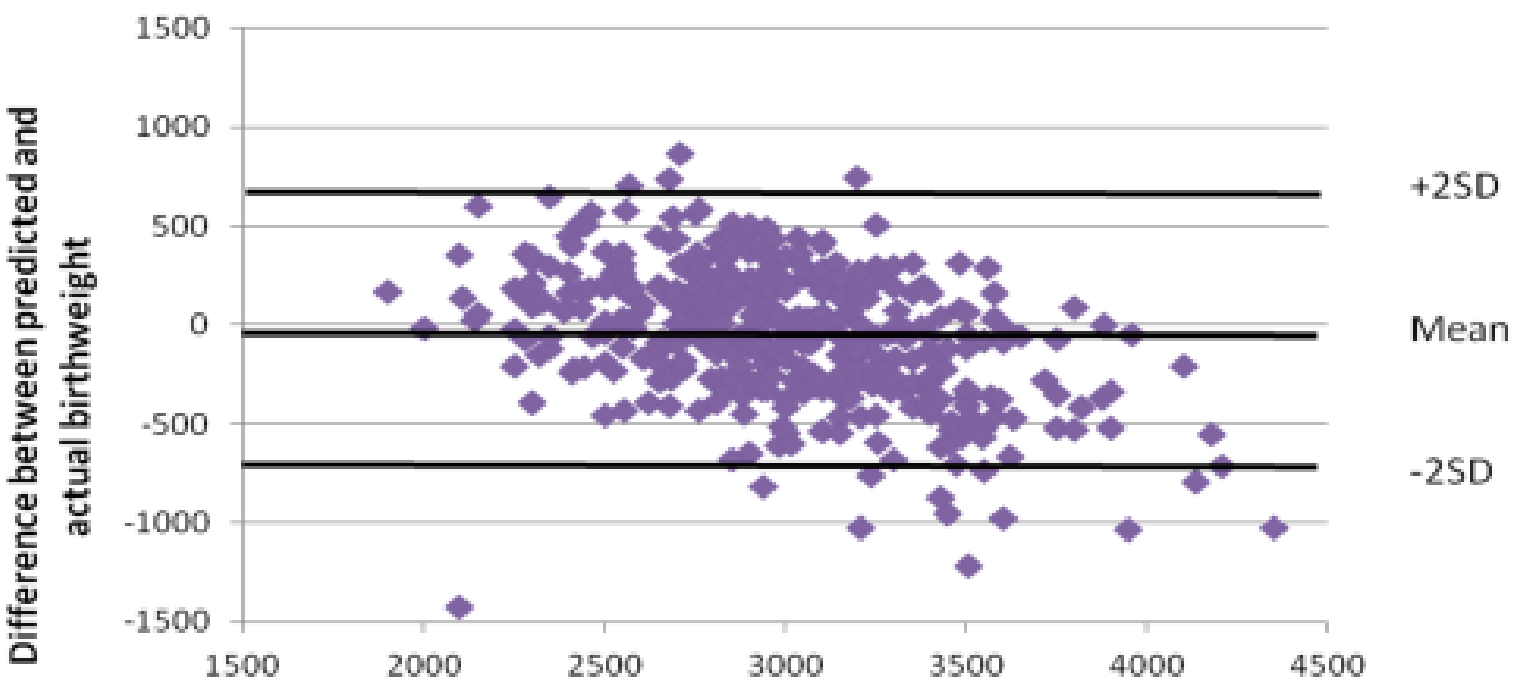

Birthweight

Figure 1. Altman and Bland plot showing the level of agreement between actual birthweight and difference between predicted and actual birthweight using Hadlock formula 4 (A) and Campbell formula (B). 


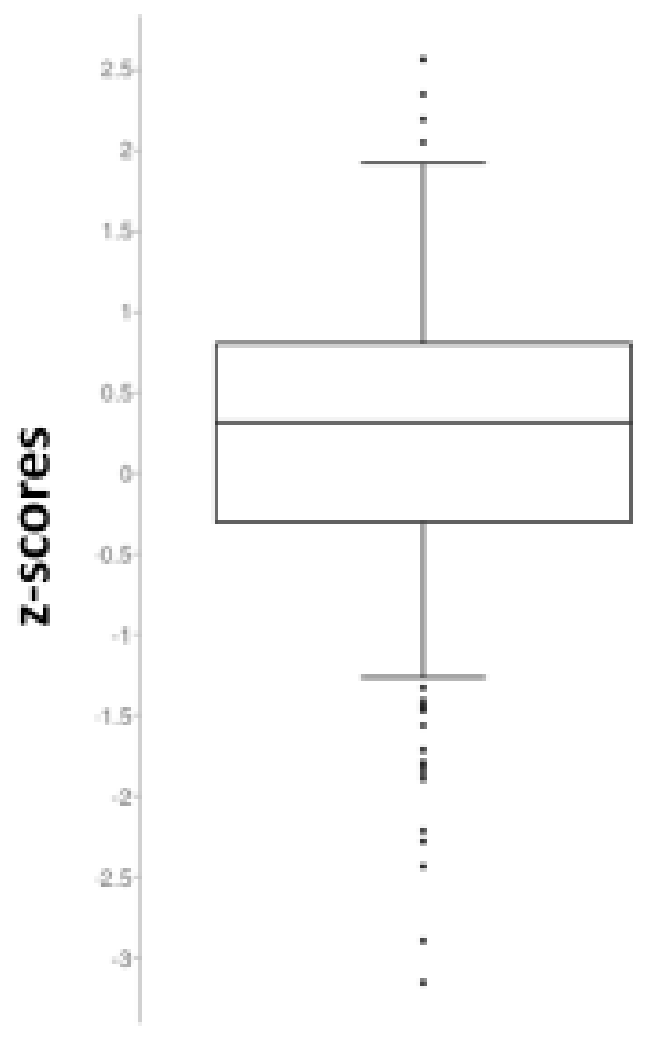

Hadlock 4 formula

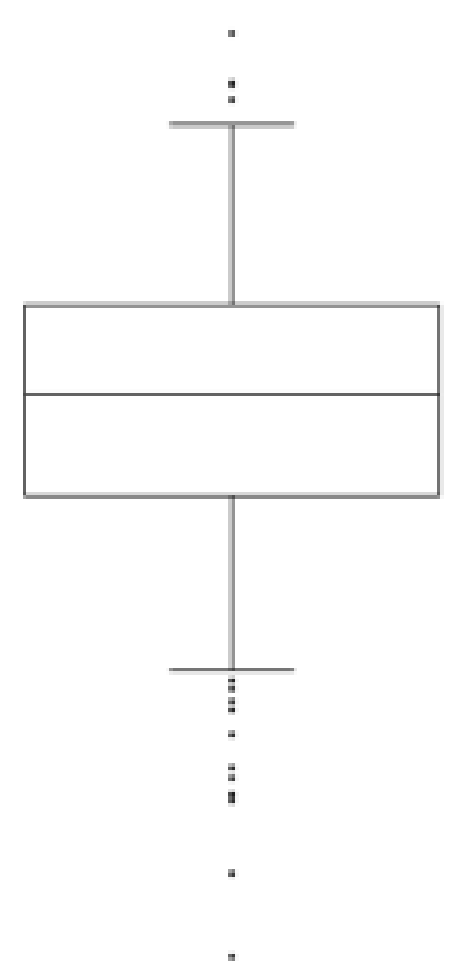

Campbell formula

Figure 2. Box plot showing the distribution of z-scores using the Hadlock formula 4 (Median: 0.32, Minimum: -3.15 , Maximum: 2.56, First quartile: -0.295 , Third quartile: 0.8 , Interquartile Range: 1.095) and Campbell formula (Median: -0.06, Minimum: -3.42, Maximum: 2.10, First quartile: -0.66 , Third quartile: 0.47 , Interquartile Range: 1.13 ).

\section{Discussion}

The main aim of prenatal care is the prevention of fetal and maternal morbidity and mortality. In order to prevent complications, timely intervention is needed for patients at risk. If the method used for identification of at risk patients lacks sensitivity and specificity, any trial of intervention will be compromised. It is a challenge to estimate the actual fetal/ birthweight from ultrasound scan. Despite these limitations, clinicians routinely take decisions based on ultrasound estimation of fetal weight. Therefore, it is important to determine the validity of ultrasound EFW formula for a given population. This is the largest study to evaluate the accuracy of established EFW formulae in predicting actual birthweight in a Sri Lankan population. Our study demonstrated that the overall ability of available EFW formulae including the commonly using Hadlock formula 4 is limited in predicting the actual birthweight. Wide systematic and random errors exist with all established EFW formulae in predicting birthweights in a Sri Lankan population. Moreover, all most all the formulae overestimate the actual birthweights in low birthweight babies. Therefore, it is very important to keep this in mind when making decision on the timing of delivery in low birthweight babies. As we cannot recommend any formula that suits our population, interpretation of ultrasound EFW should be done cautiously until we develop EFW formulae suitable for our population.

Only one previous study attempted to assess the accuracy of established EFW formula in predicting fetal weight in a Sri Lankan population. Kumara et al. examined 86 singleton pregnancies and the relationship of actual birth weight with that of the ultrasonographic estimation of EFW using six different formulae [7-9, 14]. They tried to validate these formulae using correlation method. However, it is not appropriate to use correlation coefficient or regression analysis to compare actual and estimated birthweight [15].

Many factors influence the accuracy of estimated fetal weight. The formulae included above were based on typical Western populations. Therefore, systematic and random errors are larger for small fetuses. It is thought that maternal adiposity affects the accuracy of individual ultrasound fetal measurements because high BMI affects image quality. However, maternal body mass index does not have a significant influence on measurement error [16, 
17]. Interestingly, our study mean BMI was $20 \mathrm{kgm}-2$ therefore, BMI should not have influenced the measurements. Operator experience plays an important role in accurate fetal weight estimates. There is a learning curve in estimating fetal weight, significant improvement can be achieved by training up to 24 months [18]. Even with experience, there are inter-observer differences in measurements. Chang et al. measured intra- and interobserver errors in a series of 40 patients, scanned by two experienced operators [19]. They demonstrated intraobserver differences (SD) of less than $1 \mathrm{~mm}$ for linear and less than $4 \mathrm{~mm}$ for circumference measurements would result in to intra-observer differences of less than $75 \mathrm{~g}$ in EFW. Furthermore, inter-observer differences of less than $2 \mathrm{~mm}$ for linear and less than 6-8 mm circumference measurements result in to inter-observer differences of less than 85 g, or approximately 3.5\%, in EFW [19]. The main strength of our study is that all the ultrasound examinations were carried out by one accredited operator therefore inter-observer difference is zero. We did not take multiple measurements from each biometry parameter; this limits the calculation of intra-observer variation.

The main limitation of many existing validation studies is that they included births that occurred over a wide range of days after the last ultrasound examination. We scanned most of the study subjects within 3 days of birth. It has been demonstrated that mean percentage weight differences are not significantly different from day 0 on days 1, 2 and 3 of delivery from last scan date [20]. Other limitation of validation studies is that of generalizability. Our study showed that mean birthweight at term in our study population is comparable to the reference range derived from the global reference range adapted to the Sri Lankan population based on the WHO survey (Mean birthweight at 40 weeks 3079 (SD 399)) [21].

In conclusion no preferred formula for the ultrasound EFW was determined from this study. The size of the random measurement errors remains a major limitation to confident use of these formulae in clinical practice. Therefore, clinicians should be aware of these limitations before taking clinical decisions based on ultrasound EFW.

\section{References}

1. Baschat AA. Neurodevelopment following fetal growth restriction and its relationship with antepartum parameters of placental dysfunction. Ultrasound Obstetrics and Gynaecology 2011; 37: 501-14.

2. Salomon LJ. Early fetal growth: concepts and pitfalls. Ultrasound Obstetrics and Gynaecology 2010; 35: 385-9.

3. Peregrine E, O'Brien P, Jauniaux E. Clinical and ultrasound estimation of birth weight prior to induction of labor at term. Obstetrics and Gynaecology 2007; 29: 304-9.

4. Hendler I, Blackwell SC, Bujold E, Treadwell MC, Wolfe HM, Sokol RJ, Sorokin Y. The impact of maternal obesity on midtrimester sonographic visualization of fetal cardiac and craniospinal structures. International Journal of Obesity 2004; 28: 1607-11.
5. Kumara DMA, Perera H. Evaluation of six commonly used formulae for sonographic estimation of fetal weight in a Sri Lankan population. Sri Lankan Journal of Obstetrics and Gynaecology 2009; 31: 20-33.

6. Loughna P, Chitty L, Evans T, Chudleigh T. Fetal size and dating: charts recommended for clinical obstetric practice. Ultrasound 2009; 17: 161-7.

7. Hadlock FP, Harrist RB, Carpenter RJ, Deter RL, Park SK. Sonographic estimation of fetal weight. The value of femur length in addition to head and abdomen measurements. Radiology 1984; 150: 535-40.

8. Hadlock FP, Harrist RB, Sharman RS, Deter RL, Park SK. Estimation of fetal weight with the use of head, body, and femur measurements a prospective study. American Journal of Obstetrics and Gynaecology 1985; 151: 333-7.

9. Hadlock FP, Harrist RB, Fearneyhough TC. Use of femur length/abdominal circumference ratio in detecting the macrosomic fetus. Radiology 1985; 154: 503.

10. Campbell S, Wilkin D. Ultrasonic measurement of fetal abdominal circumference in the estimation of fetal weight. British Journal of Gynaecology 1975; 82: 689-97.

11. Merz E, Lieser H, Schicketanz KH, Härle J. Intrauterine fetal weight assessment using ultrasound. A comparison of several weight assessment methods and development of a new formula for the determination of fetal weight. Ultraschall in der Medizine 1988; 9: 15-24.

12. Warsof SL, Gohari P, Berkowitz RL, Hobbins JC. The estimation of fetal weight by computer-assisted analysis. American Journal of Obstetrics and Gynaecology 1977; 128: 88I.

13. Thurnau GR, Tamura RK, Sabbagha R, Depp OR, Dyer A, Larkin R, Lee T, Laughlin C. A simple estimated fetal weight equation based on real-time ultrasound measurements of fetuses less than thirty-four weeks' gestation. American Journal of Obstetrics and Gynaecology 1983; 145: 557-61.

14. Shepard MJ, Richards VA, Berkowitz RL, Warsof SL, Hobbins JC. An evaluation of two equations for predicting fetal weight by ultrasound. American Journal of Obstetrics and Gynaecology 1982; 142: 47-54.

15. Altman DG, Bland JM. Measurement in medicine: the analysis of method comparison studies. Statistician 1983; 32: 307-17.

16. Farrell T, Holmes R, Stone P. The effect of body mass index on three methods of fetal weight estimation. British Journal of Gynaecology 2002; 109: 651-7.

17. Ott WJ, Doyle S, Flamm S. Accurate ultrasonic estimation of fetal weight. American Journal of Perinatology 1985; 2: 178-82.

18. Predanic M, Cho A, Ingrid F, Pellettieri J. Ultrasonographic estimation of fetal weight: acquiring accuracy in residency. Journal of Ultrasound Medicine 2002; 21: 495-500.

19. Chang TC, Robson SC, Spencer JAD, Gallivan S. Ultrasonic fetal weight estimation: analysis of inter- and intra-observer variability. Journal of Clinical Ultrasound 1993; 21: 515-9.

20. Cohen JM, Hutcheon JA, Kramer MS, Joseph KS, Abenhaim H, Platt RW. Influence of ultrasound-to-delivery interval and maternal-fetal characteristics on validity of estimated fetal weight. Ultrasound Obstetrics and Gynaecology 2010; 35: 434-41.

21. Mikolajczyk RT, Zhang J, Betran AP, Souza JP, Mori R, Gülmezoglu AM, Merialdi M. Aglobal reference for fetal-weight and birthweight percentiles. Lancet 2011; 377: 1855-61. 